\title{
Co-Free High-Entropy Alloys Powders Immobilized by Electrospray and Microfluidics for Decolorization of Azo Dye
}

\author{
Shikai Wu ${ }^{1} \cdot$ Wei Gao ${ }^{2} \cdot \mathrm{Tao}_{\mathrm{Lu}}{ }^{1} \cdot$ Ye Pan ${ }^{1}$ \\ Received: 30 September 2019 / Revised: 2 November 2019 / Published online: 21 January 2020 \\ (c) The Chinese Society for Metals (CSM) and Springer-Verlag GmbH Germany, part of Springer Nature 2020
}

\begin{abstract}
In recent years, high-entropy alloys (HEAs) have received more and more attention due to their unique microstructure and properties. Several researchers have reported that some ball-milled (BM) HEAs powders possess prominent decolorization performance for azo dyes. Three kinds of Co-free HEA powders ( $\mathrm{AlCrFeMn}, \mathrm{AlCrFeNi}$ and $\mathrm{FeCrNiMn}$ ) have been synthesized by ball milling in this work, of which AlCrFeMn shows the best decolorization efficiency for DB6 aqueous solution. However, at this time, the BM HEAs are in powder state and not easy to be reused, so the loss rate of the powders is high during the reaction. Sometimes, the reaction between reacted the powders and the dye solution is too fast to control. While, in order to solve these problems, this work proposes to immobilize bare BM AlCrFeMn HEA powders in calcium alginate beads (CABs) by electrospray and microfluidics. Through four cycles of reaction, the loss rate of the AlCrFeMn powders can be reduced from 40 to $5 \mathrm{wt} \%$ if the powders are immobilized by CABs with an average diameter of $0.55 \mathrm{~mm}$ obtained at the DC voltage of $30 \mathrm{kV}$. In addition, in the four cycles of experiment, the AlCrFeMn HEA-CABs with an average diameter of $0.55 \mathrm{~mm}$ shows better stability and easier separation than that of the bare AlCrFeMn powders. These findings provide new ideas for HEAs to decolorize azo dyes and are of great significance for protecting freshwater resources.
\end{abstract}

Keywords High-entropy alloys $\cdot$ Ball-milled $\cdot$ Decolorization performance $\cdot$ Calcium alginate beads $\cdot$ Electrospray and microfluidics

\section{Introduction}

Today, the amount of freshwater resources is still not enough for the needs of people's daily lives [1-4]. But, with the rapid development of the printing and dyeing industries, various dyes are still discharged into freshwater [5-8]. Among

Shikai Wu and Wei Gao have contributed equally to this work.

Available online at http://link.springer.com/journal/40195.

Electronic supplementary material The online version of this article (https://doi.org/10.1007/s40195-019-00997-x) contains supplementary material, which is available to authorized users.

Ye Pan

panye@seu.edu.cn

1 School of Materials Science and Engineering, Jiangsu Key Laboratory for Advanced Metallic Materials, Southeast University, Nanjing 211189, China

2 School of Energy and Environment, Key Laboratory of Energy Thermal Conversion and Control of Ministry of Education, Southeast University, Nanjing 211189, China these dyes, synthetic azo dyes are widely used, and they are toxic and mutagenic [9-12]. People are increasingly aware of the harmful effects of azo dyes and achieve water circulation by removing them from wastewater [4, 9, 13-15]. Although many natural and synthetic materials have been used to remove azo dyes from wastewater, there is still much room for improvement in materials to maximize resource utilization [16-18].

At present, most of the reported HEAs contain cobalt element, which is listed as a kind of strategic material with high price in many countries. In addition, HEAs, usually with single-phase solid solution structure, are consisted of at least four principal metallic elements with equimolar or near-equimolar fractions [19-21]. So, we design and synthesize three kinds of cobalt-free HEAs (AlCrFeMn, AlCrFeNi and $\mathrm{FeCrNiMn)}$ with equal-atomic ratios by ball milling. Among the three kinds of BM HEAs powders, we find that the bare BM AlCrFeMn powders show the fastest decolorization speed for DB6, 3 times faster than that of bare BM MgZn-based amorphous alloy, which is the best one of the alloy materials reported so far [20-23]. However, the bare 
HEAs powders are easy to lose, easy to agglomerate and not conducive to recycling in the process of decolorization $[20,21]$. In order to solve these problems, we entrap the bare $\mathrm{AlCrFeMn}$ powders in the calcium alginate beads (CABs) for the first time in this work. The purpose of entrapping the $\mathrm{AlCrFeMn}$ powders in the $\mathrm{CABs}$ is to improve the dispersibility of the powders, reduce the loss rate of the powders, improve the reaction stability of the powders and make the powders easier to be reused.

\section{Experimental}

\subsection{Synthesis of Bare BM HEAs Powders}

The raw materials were high purity (more than $99.9 \mathrm{wt} \%$ ) of aluminum, chromium, iron, manganese and nickel powders with particle sizes between 10 and $45 \mu \mathrm{m}$, and they were used to synthesize AlCrFeMn, AlCrFeNi and $\mathrm{FeCrNiMn}$ HEAs powders by ball milling. The high-energy planetary ball mill rotated at $350 \mathrm{r} / \mathrm{min}$, and the ball-to-powders ratio was 15:1. Zirconia jars and balls were used as grinding media, and stearic acid was used as the process control agent to prevent supercooled soldering. Before ball milling, highpurity argon was charged into the zirconia jars to prevent oxidation of the raw powders. After milling for $60 \mathrm{~h}$, the powders were removed from the zirconia jars and stored in a vacuum drying oven for further characterization.

\subsection{Immobilization of Bare AICrFeMn HEA Powders in CABs}

In this work, $\mathrm{AlCrFeMn}$ showed the fastest rate in decoloring DB6. Therefore, the bare BM AlCrFeMn powders were selected as an example and immobilized in the CABs (denoted as $\mathrm{AlCrFeMn} \mathrm{HEA-CABs)} \mathrm{by} \mathrm{combining} \mathrm{electro-}$ spray and microfluidic device, and the schematic diagram is shown in Fig. S1. The first step was to prepare sodium alginate solution with mass to volume ratio of $2 \%(2 \mathrm{w} / \mathrm{v} \%)$, then $0.1 \mathrm{~g}$ of $\mathrm{AlCrFeMn}$ powders and $10 \mathrm{~mL}$ of the prepared sodium alginate solution were evenly mixed, and they were inhaled into a syringe. While, the syringe was fixed on the microfluidic device, and the push speed was $1 \mathrm{~mL} / \mathrm{min}$. The mixture of the $\mathrm{AlCrFeMn}$ powders and sodium alginate solution was sprayed into $\mathrm{CaCl}_{2}$ solution (4 w/v\%), and $\mathrm{Ca}^{2+}$ was cross-linked with sodium alginate to form $\mathrm{CABs}$, and the $\mathrm{AlCrFeMn}$ powders were evenly wrapped in these beads. Different diameters of CABs could be obtained by adjusting the DC voltages of the electrostatic spray device. The electrostatic DC voltages were $0 \mathrm{kV}, 10 \mathrm{kV}, 20 \mathrm{kV}$ and $30 \mathrm{kV}$ in this work, respectively. In order to verify the effect of pure CABs on azo dye DB6, pure CABs with four diameters are prepared at the four DC voltages, respectively. The pure
CABs and the HEA-CABs obtained at the same voltages own the same diameters. After freeze-drying, the AlCrFeMn HEA-CABs were stored in a vacuum drying oven for further characterization.

\subsection{Batch Experiments}

DB6 $\left(\mathrm{C}_{32} \mathrm{H}_{20} \mathrm{~N}_{6} \mathrm{~S}_{4} \mathrm{O}_{14} \mathrm{Na}_{4}\right)$ was purchased from Tianjin Hailan Chemical Pigment Co., Ltd. During the predetermined reaction time interval, about $3 \mathrm{~mL}$ of solution was taken out from the dye solution, the HEAs powders were removed by centrifugation, and the HEAs-CABs were filtered through a sieve. The solution was then scanned with an UV-Vis spectrophotometer (UV-Vis) at a wavelength in the range of $400-800 \mathrm{~nm}$. The DB6 solution was stirred by a mechanical agitator at a fixed rate in a beaker, which was placed in a $25^{\circ} \mathrm{C}$ water bath during the course of the decoloration reaction. For each decolorization test, $0.1 \mathrm{~g}$ of one of the three HEAs (AlCrFeMn, AlCrFeNi and $\mathrm{FeCrNiMn}$ ) powders or the AlCrFeMn HEA-CABs containing $0.1 \mathrm{~g}$ of $\mathrm{AlCrFeMn}$ powders were added to $200 \mathrm{~mL}$ of $200 \mathrm{mg} / \mathrm{L}$ azo dye DB6 solution for reaction. Distilled water was used as solvent without adding any other reagents during the reaction.

\subsection{Analytical Methods}

The crystal structure of the samples was investigated by $\mathrm{X}$-ray diffraction (XRD, D8 advancement, copper $K \alpha$ ) and transmission electron microscopy (TEM, Tecnai FEI F20). The morphology of the samples was investigated by optical microscope (OM, DMI300M) or scanning electron microscopy (SEM, JSM-7100F). The statistical distribution of the powders particle sizes were recorded using laser particle size analyzer (FJUL1076), and the diameters of the HEAsCABs were measured by the software of image pro plus. The surface area analysis of the samples was performed using Brunauer-Emmett-Teller (BET, 3 h-2000beta) technique. The UV-Vis absorption spectroscopy was recorded using UV-Vis spectrophotometer (TU-1810). A laboratory electromechanical stirrer (JB90-D) was set to rotate at a certain speed to evenly distribute the HEA powders or the HEACABs in the dye solution.

\section{Results and Discussion}

\subsection{Characterization of Bare HEAs Powders}

The SEM images of AlCrFeMn, AlCrFeNi and FeCrNiMn powders obtained by ball milling are shown in Fig. 1. As can be seen from Fig. 1, the average particle sizes of $\mathrm{AlCrFeMn}$ and $\mathrm{AlCrFeNi}$ powders are relatively uniform and finer, while, the average particle size of FeCrNiMn powders is 

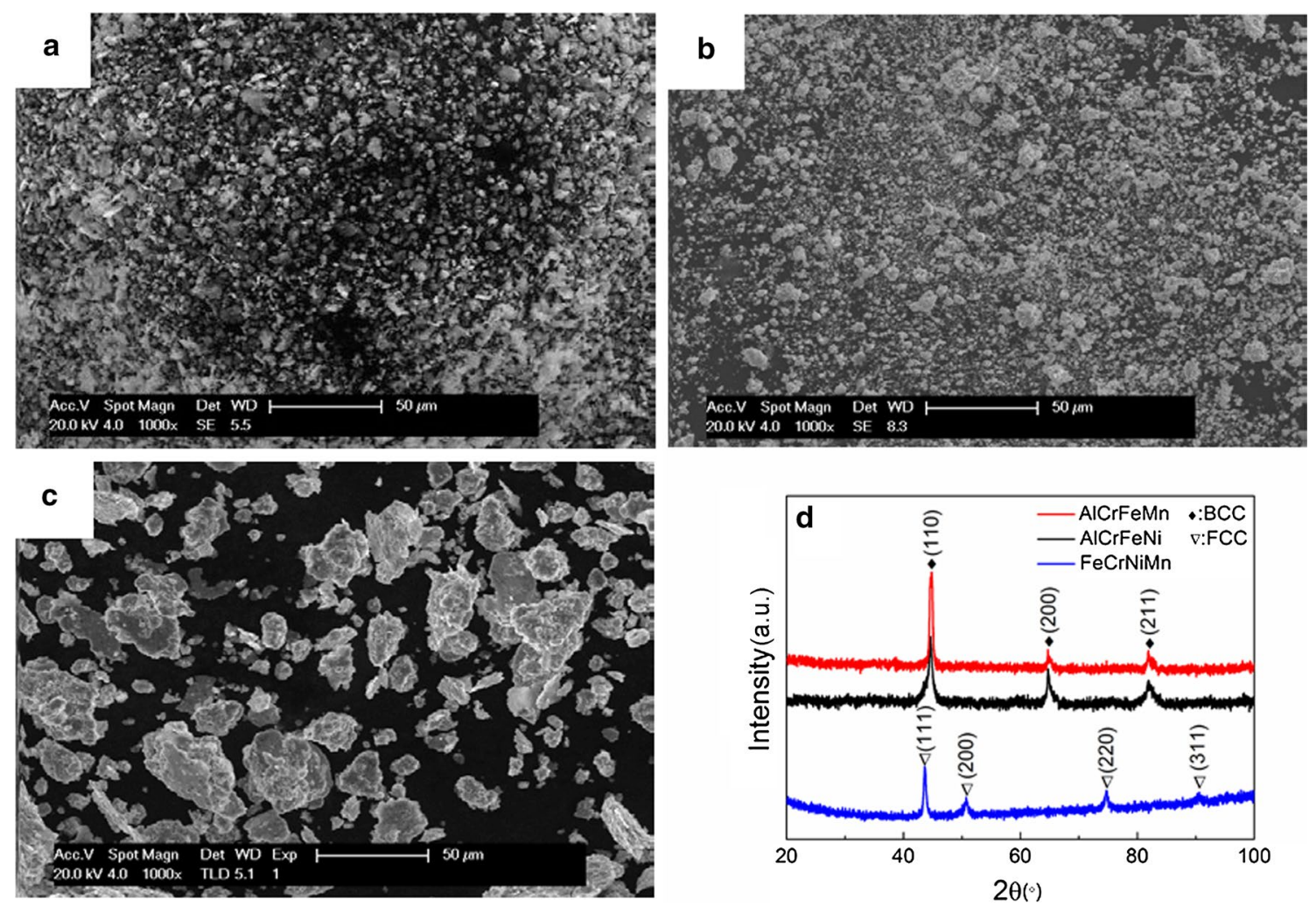

Fig. 1 SEM images of the bare BM AlCrFeMn HEA powders a, the bare BM AlCrFeNi HEA powders b, the bare BM FeCrNiMn HEA powders $\mathbf{c}$ before decoloration, $\mathbf{d}$ X-ray diffraction curves of the bare $\mathrm{BM} \mathrm{AlCrFeMn}, \mathrm{AlCrFeNi}$ and FeCrNiMn HEAs powders before decoloration

relatively larger. As presented in Fig. S2, the average particle sizes of $\mathrm{AlCrFeMn}, \mathrm{AlCrFeNi}$ and $\mathrm{FeCrNiMn}$ powders are about $4.2 \mu \mathrm{m}, 3.8 \mu \mathrm{m}$ and $21.3 \mu \mathrm{m}$, respectively. The X-ray diffraction curve in Fig. 1d reveals that there is only a single body-centered cube (BCC) phase in $\mathrm{AlCrFeMn}$ or $\mathrm{AlCrFeNi}$ and a single face-centered cube (FCC) phase in FeCrNiMn. The XRD result of these three alloys ( $\mathrm{AlCrFeMn}, \mathrm{AlCrFeNi}$ and $\mathrm{FeCrNiMn}$ ) indicates that any of them is containing a single solid solution phase.

\subsection{Characterization of AICrFeMn HEA-CABs}

The picture of the four kinds of AlCrFeMn HEA-CABs (from the left to the right) prepared at the four DC voltages $(0 \mathrm{kV}, 10 \mathrm{kV}, 20 \mathrm{kV}$ and $30 \mathrm{kV})$ is presented in Fig. S3a. The relationship between the diameters of the four kinds of the AlCrFeMn HEA-CABs and the voltages is shown in Fig. S3b. According to statistics, the average diameters of the four HEA-CABs obtained under the four voltages are $3.27 \mathrm{~mm}, 1.58 \mathrm{~mm}, 0.93 \mathrm{~mm}$ and $0.55 \mathrm{~mm}$, respectively. The results reveal that the AlCrFeMn HEA-CABs obtained under different voltage conditions have different diameters. The higher the voltage, the smaller the diameters of the HEAs-CABs. Figure 2 shows that the images taken by the
OM of the AlCrFeMn HEA-CABs obtained at $0 \mathrm{kV}, 10 \mathrm{kV}$, $20 \mathrm{kV}$ and $30 \mathrm{kV}$, respectively. In Fig. 2a and b, since the diameters of the HEAs-CABs are relatively large, and the beads contain more powder, while the light cannot penetrate the beads, so we cannot see the uniform distribution of the powder in the CABs. But it can be clearly seen from Fig. $2 \mathrm{c}$ and $\mathrm{d}$ that the $\mathrm{AlCrFeMn}$ powders are uniformly distributed inside the CABs. The uniform distribution of the powders is beneficial to the reaction between the powders and DB6 inside the CABs.

The SEM images of the AlCrFeMn HEA-CABs with an average diameter of $0.55 \mathrm{~mm}$ obtained at $30 \mathrm{kV}$ are revealed in Fig. 3. Since the HEA-CABs must be freezedried before they are observed by SEM, we cannot see the tiny channels on the surface or inside the HEA-CABs clearly. As tested by the BET method, the average size of the micropores on the HEA-CABs is about $2.9 \mathrm{~nm}$, which is significantly smaller than the average particle size of the bare AlCrFeMn powders $(4.2 \mu \mathrm{m})$, so that the DB6 solution can flow into the CABs and react with the HEA powders, but the HEA powders cannot be out from the CABs. So, the loss rate of the $\mathrm{AlCrFeMn}$ powders is greatly reduced. 


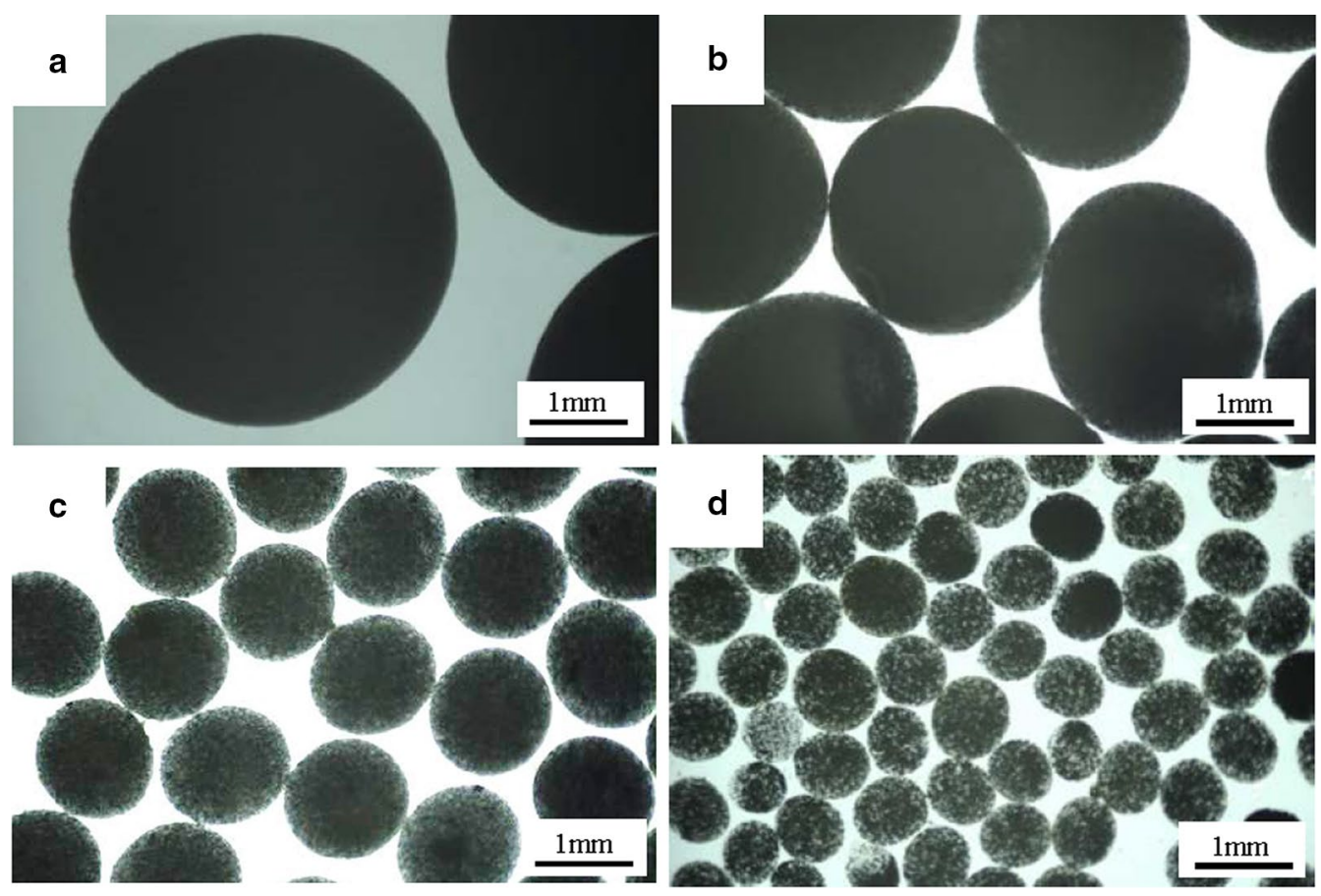

Fig. 2 Optical microscope images of the four kinds of AlCrFeMn HEA-CABs at the four different DC voltages: a $0 \mathrm{kV}, \mathbf{b} 10 \mathrm{kV}$, c $20 \mathrm{kV}$, d $30 \mathrm{kV}$
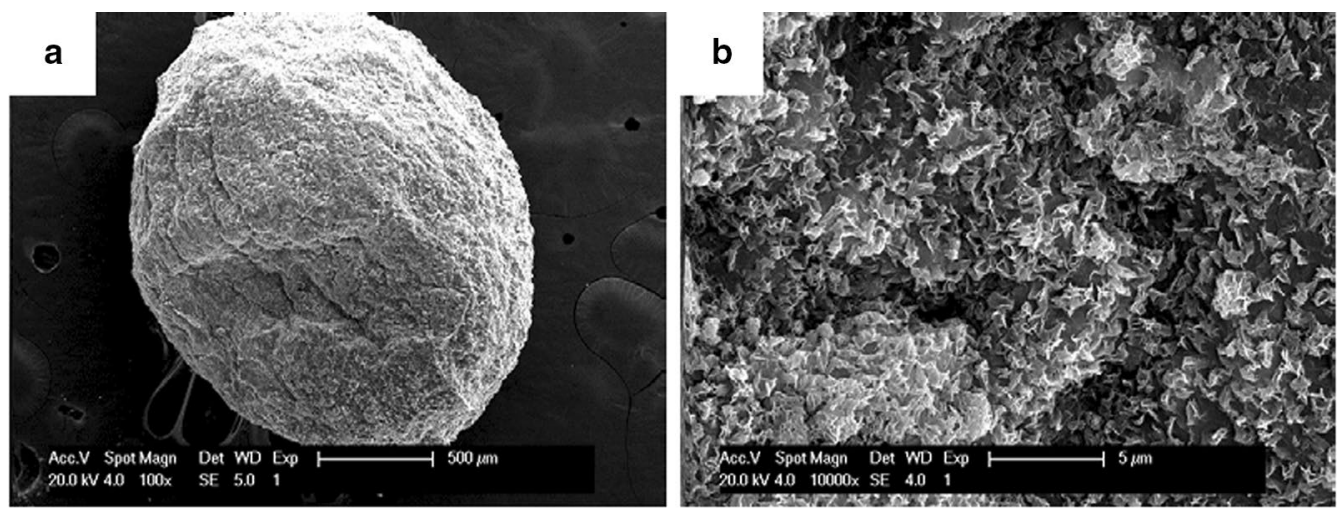

Fig. 3 SEM images of the AlCrFeMn HEA-CABs obtained at the DC voltage of $30 \mathrm{kV}$ after freeze-drying: a low magnification, b large magnification

\subsection{Decoloration Efficiency}

\subsubsection{Comparison of the Decoloration Efficiency of DB6 by the Three HEAs}

Figure $4 \mathrm{a}$ shows the decolorization fitting curves of $200 \mathrm{mg} / \mathrm{L}$ DB6 decolorized by $0.5 \mathrm{~g} / \mathrm{L}$ AlCrFeMn, AlCr$\mathrm{FeNi}$ and $\mathrm{FeCrNiMn}$ during the decomposition process at $25{ }^{\circ} \mathrm{C}$ and initial $\mathrm{pH}=7$. Figure $4 \mathrm{~b}$ presents the corresponding decolorization times obtained after fitting of the three HEAs. The decolorization times of $\mathrm{AlCrFeMn}, \mathrm{AlCr}-$ FeNi and FeCrNiMn are 12.6 min, 35.3 min and 89.6 min, respectively. The efficiencies of these three-component alloys (AlCrFeMn, $\mathrm{AlCrFeNi}$ and $\mathrm{FeCrNiMn}$ ) decolorizing DB6 are very different.

As we know, the activity of HEAs powders is closely related to their compositions, morphology, phases, particle sizes and distribution $[9,10]$. Fine-grained, uniformly distributed, surface-roughened powders alloys generally have more active sites than that of larger-size powders alloys of the same mass [9,24-26]. The more active sites in the powders, the better the reaction of the powders with the azo dyes [26]. The BCC phase is hard and brittle, and the FCC is soft and tough $[24,27]$. So, under the same ball milling 

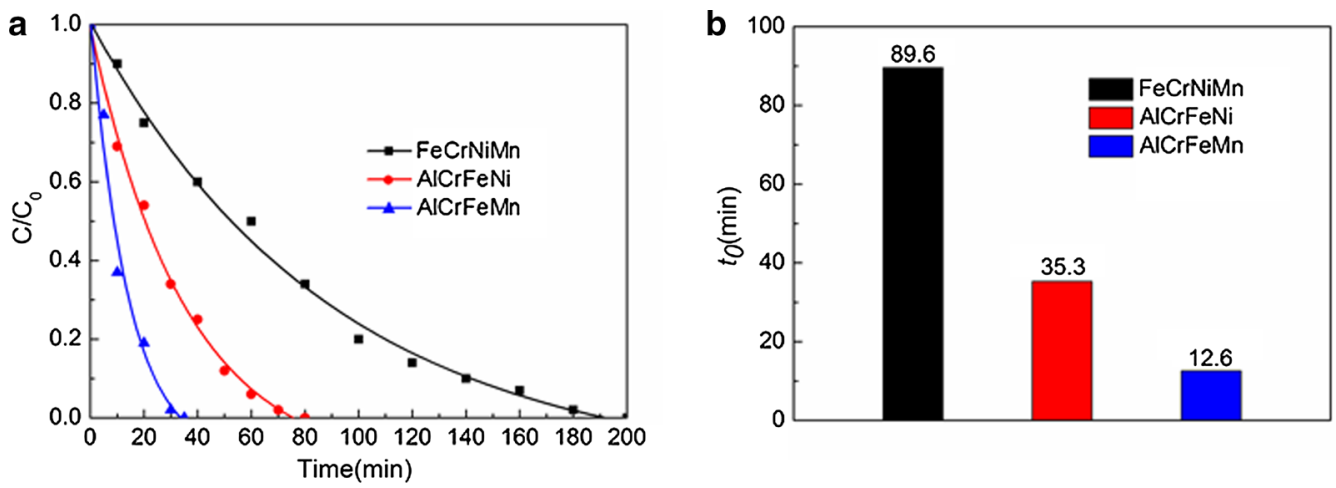

Fig. 4 Comparison of the decoloration efficiency of DB6 by $0.5 \mathrm{~g} / \mathrm{L}$ AlCrFeMn, AlCrFeNi and FeCrNiMn after fitting at $25^{\circ} \mathrm{C}$ : a decoloration curves, $\mathbf{b}$ fitting time

condition, the average particle sizes of the HEAs powders with $\mathrm{BCC}$ phases are finer than that of the HEAs powders with FCC phases $[20,24]$. The average particle sizes of $\mathrm{AlCrFeMn}(4.2 \mu \mathrm{m})$ and $\mathrm{AlCrFeNi}(3.8 \mu \mathrm{m})$ are finer than that of FeCrNiMn $(21.3 \mu \mathrm{m})$. In addition, according to the activity series of metals, the activity rank of the constituent elements in the three HEAs is $\mathrm{Al}>\mathrm{Mn}>\mathrm{Cr}>\mathrm{Fe}>\mathrm{Ni}[28$, 29]. For the above reasons, the overall activity of $\mathrm{AlCrFeMn}$ is better than that of $\mathrm{AlCrFeNi}$, whose activity is better than that of FeCrNiMn. So, the order of decolorization efficiency of these three alloys is $\mathrm{AlCrFeMn}>\mathrm{AlCrFeNi}>\mathrm{FeCrNiMn}$.

\subsubsection{Decoloration of DB6 by Pure CABs, Bare AICrFeMn HEA and HEA-CABs}

\subsubsection{Comparision of Pure CABs, Bare AICrFeMn HEA} and AICrFeMn HEA-CABs Pure CABs are used for contrast experiment and the experimental results are presented in Fig. 5a. It can be found from Fig. 5a that the pure CABs have a certain adsorption effect on DB6 solution in the first $2 \mathrm{~min}$, but there is no adsorption effect after $2 \mathrm{~min}$. Figure $5 \mathrm{~b}$ shows the comparison of the bare HEA powders and the four kinds HEA-CABs (after removing the adsorption effect of the pure CABs) to decolorize DB6. It is presented in Fig. $5 b$ that the decolorization rates of all the AlCrFeMn HEA-CABs are lower than that of the bare AlCrFeMn HEA powders. This phenomenon is due to the fact that calcium alginate has a certain hindrance to the contact of powders with dye, which is a disadvantage of HEAs-CABs. Although we have sacrificed the decolorization rate to some extent, we can achieve more goals, so we can choose whether to entrap the HEAs powders according to the needs of the actual application. In addition, the rate of decolorizing DB6 by HEAs-CABs with smaller diameters (obtained at higher voltages) is faster than that of the HEAs-CABs with larger diameters (obtained at lower voltages).
Figure $5 \mathrm{c}$ provides the fitting time $\left(t_{0}\right)$ of decolorizing DB6 by the bare HEA powders and the four HEAs-CABs. The fitting time for the bare HEA powders is $11.2 \mathrm{~min}$, and other fitting times for the four kinds of HEA-CABs are $19.8 \mathrm{~min}, 21.1 \mathrm{~min}, 23.7 \mathrm{~min}$ and $27.5 \mathrm{~min}$, respectively. The schematic diagram for the decolorization of DB6 by $\mathrm{AlCrFeMn} \mathrm{HEA-CABs} \mathrm{is} \mathrm{displayed} \mathrm{in} \mathrm{Fig.} \mathrm{S4.}$

3.3.2.2 Comparison of Stability and Reusability The comparison curves of the pure CABs, the HEA-CABs and the bare HEA powders on decolorizing DB6 are shown in Fig. 6a. In order to compare the stability and reusability of the bare $\mathrm{AlCrFeMn}$ powders and the AlCrFeMn HEACABs for the decolorization of DB6, the bare powders and the HEA-CABs to decolorize DB6 in four cycles are evaluated under the identical experimental conditions. Figure $6 \mathrm{~b}$ shows the decoloration curves of DB6 by the bare $\mathrm{AlCrFeMn}$ powders in four cycles, and Fig. $6 \mathrm{c}$ shows the decoloration curves of DB6 by the HEA-CABs with an average diameter of $0.55 \mathrm{~mm}$ in four cycles (after removing the adsorption effect of the pure CABs). After four cycles, the decolorization efficiency of the bare $\mathrm{AlCrFeMn}$ powders is significantly reduced, but the decolorization efficiency of the HEA-CABs is almost unchanged. It means that the HEA-CABs are able to be reused for multiple cycles and exhibit no significant loss of activity. At the end of one cycle, the HEA-CABs can be easily separated from the reaction solution by a simple filtering procedure. Therefore, these results indicate that the AlCrFeMn HEA-CABs have excellent long-term stability and great potential application value for their easier separation.

In addition, in order to calculate the loss rate of the HEA powders before and after immobilization, the average weight of one group of the AlCrFeMn HEA-CABs after freezedrying is about $0.244 \mathrm{~g}$, while the total weight of the HEACABs (after being freeze-dried) after four cycles is about $0.239 \mathrm{~g}$, while the total loss rate of the HEA powders is 

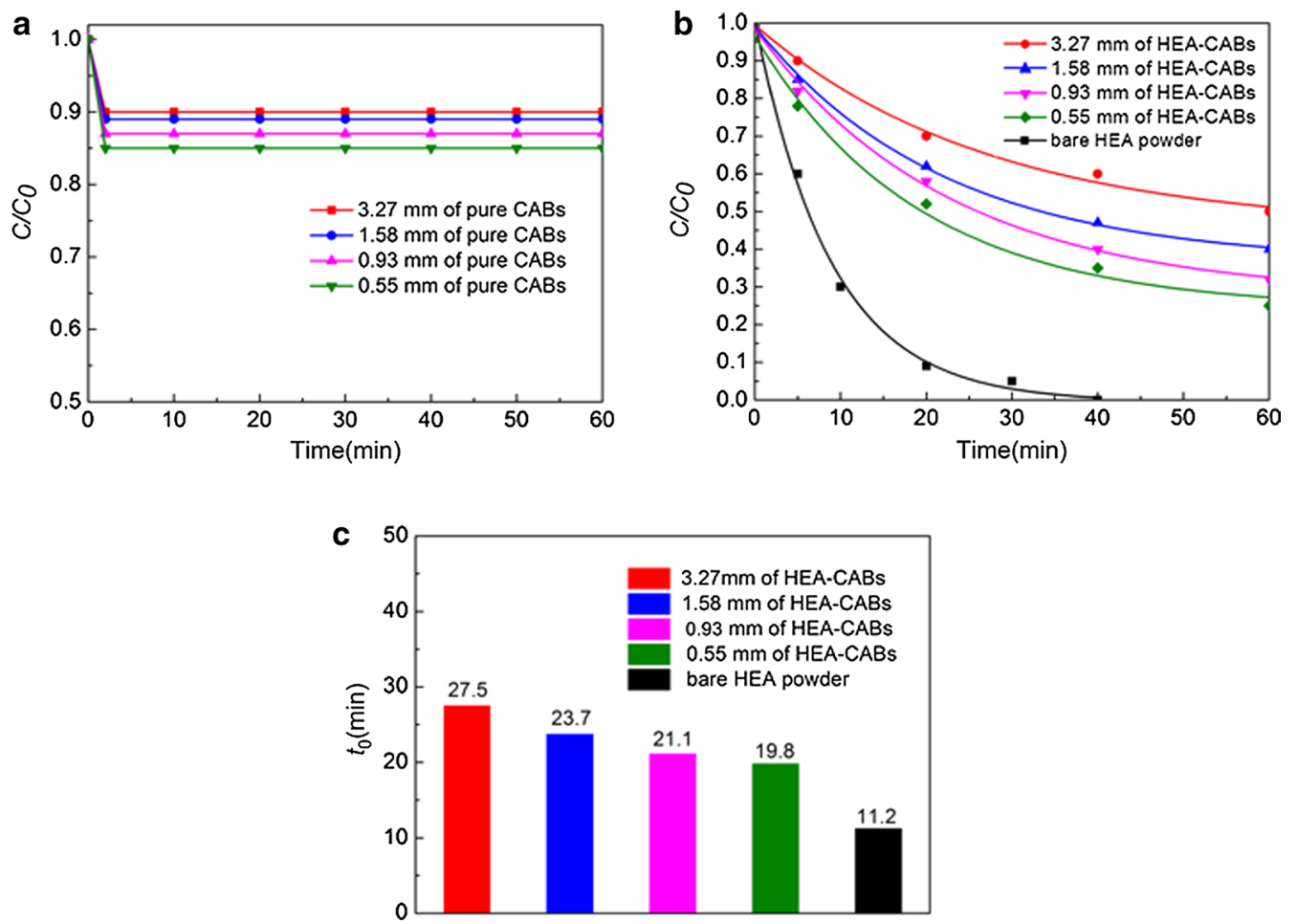

Fig. 5 Decoloration curves of DB6 by the four kinds of pure CABs a, the four kinds of AlCrFeMn HEA-CABs and the bare BM AlCrFeMn HEA powders $\mathbf{b}$, $\mathbf{c}$ comparison of the fitting time for decolorizing DB6 by the four kinds of AlCrFeMn HEA-CABs and the bare AlCrFeMn HEA powders

$5 \mathrm{wt} \%$. One group of AlCrFeMn HEA powders weighs $0.1 \mathrm{~g}$, about $0.06 \mathrm{~g}$ of powders is left after four cycles, so the total loss rate of the powders is as high as $40 \mathrm{wt} \%$, indicating that HEA powders immobilized by CABs can greatly reduce the loss rate of the powders in the procedure of decolorizing DB6.

\subsection{Kinetics and Mechanism Analysis}

Through the nonlinear curve fitting, it can be found that the decolorization process of DB6 by the samples (AlCrFeMn, $\mathrm{AlCrFeNi}$, FeCrNiMn powders or the AlCrFeMn HEA$\mathrm{CABs}$ ) is in good agreement with the pseudo-first-order exponential decay kinetics as follows:

$I=I^{0}+I^{1} \exp \left(-t / t_{0}\right)[19,20,25,29]$

where $I$ is the normalized intensity of concentration, $I^{0}$ and $I^{1}$ are fitting constants, $t$ is the reaction time, and $t_{0}$ is the time at which the intensity drops to $\mathrm{e}^{-1}$ of the initial condition. We evaluate the decolorization efficiency of the samples according to the values of $t_{0}$. The smaller the values of $t_{0}$, the higher the decolorization efficiency.

From the comparison of $\mathrm{AlCrFeMn}, \mathrm{AlCrFeNi}$ and FeCrNiMn, we know that the compositions, morphology, phases, particle sizes and distribution of the HEAs powders are closely related to their decoloration efficiency. So, when designing a HEA for decolorizing azo dyes, it is necessary to select relatively active elements as the component of the HEA, and the HEA only contains BCC phase.

Moreover, sodium alginate is the most widely used watersoluble alginate, and it can rapidly undergo ion exchange with calcium ions to form CABs with high strength and good biocompatibility [30-35]. Using this property, the alginate solution and HEAs powders can be mixed and sprayed into an aqueous solution of $\mathrm{CaCl}_{2}$ to prepare HEAs-CABs. The electrospray device can control the diameters of the HEAsCABs by adjusting the voltages, and the diameters of the obtained HEAs-CABs are different at different voltages. According to the nature property of the hydrogel balls, we can imagine that when the CABs encounter water, they will rapidly expand and form a three-dimensional network of beads with numerous tiny channels. The average particle size of the AlCrFeMn HEA powders is much larger than that of the channels inside the CABs, but the dye solution can easily pass through these channels $[32,33]$. Therefore, the AlCrFeMn powders can only react with the DB6 solution inside the CABs. The formed calcium alginate has a good mitigation and prevention effect on the surface of the HEA powders due to covering its oxide or hydroxide precipitate 

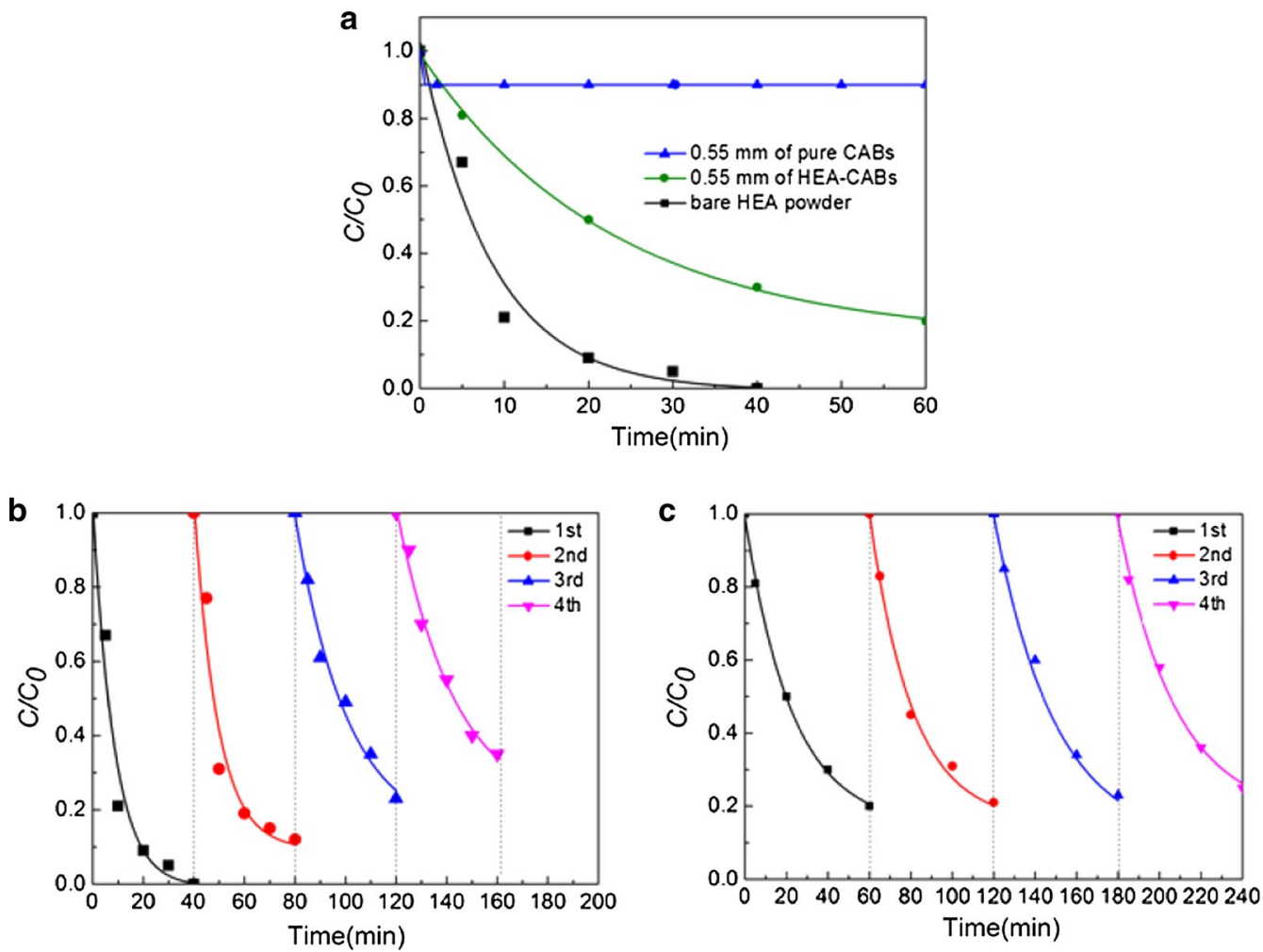

Fig. 6 a Decoloration curves of DB6 by the pure CABs with an average diameter of $0.55 \mathrm{~mm}$, the AlCrFeMn HEA-CABs with an average diameter of $0.55 \mathrm{~mm}$ and the bare AlCrFeMn HEA powders; cyclic decolorization curves of DB6 by the bare AlCrFeMn HEA powders b , the $\mathrm{AlCrFeMn} \mathrm{HEA-CABs} \mathrm{c}$

to form an inert layer, thereby achieving efficient electron transfer [33].

\section{Conclusions}

In summary, the decolorization efficiencies of the HEAs powders are closely related to their compositions, morphology, phases, particle sizes and distribution, while, the $\mathrm{AlCrFeMn}, \mathrm{AlCrFeNi}$ and $\mathrm{FeCrNiMn}$ HEAs powders obey this rule. In addition, the experimental results show that the AlCrFeMn HEA-CABs can be reused for many cycles and exhibited no significant loss of the powders and activity. Moreover, the rate at which the HEA-CABs reacts with the dye is easy to be controlled, and the HEAs-CABs are easily separated from the reaction solution by a simple filtering procedure. Furthermore, CABs is non-toxic, biocompatible, inexpensive, and the production of CABs does not require high pressure or toxic organic solvents. Therefore, it is worthwhile to study CABs as an immobilizing carrier of HEAs for decolorization of azo dyes. This work is of great significance for expanding the application of HEAs in wastewater treatment.
Acknowledgements This work was financially supported by the National Natural Science Foundation of China (Grant No. 51671056) and the Jiangsu Key Laboratory for Advanced Metallic Materials (Grant No. BM2007204). Thanks to Professor Yuanjin Zhao for his suggestion and help in this work.

\section{References}

[1] W. Raza, D. Bahnemann, M. Muneer, Catal. Today 300, 89 (2018)

[2] C.R. Marcelo, G.A. Puiatti, M.A. Nascimento, A.F. Oliveira, R.P. Lopes, J. Nanomater. 2018, 1 (2018)

[3] M. Fan, J. Hu, R. Cao, W. Ruan, X. Wei, Chemosphere 200, 330 (2018)

[4] S. Chen, G. Yang, S. Luo, S. Yin, J. Jia, Z. Li, J. Mater. Chem. A 5, 14230 (2017)

[5] Y. Yan, S. Zhang, G. Jiang, X. Li, Z. Wei, W. Chen, J. Wan, Acta Metall. Sin. (Engl. Lett.) 27, 988 (2014)

[6] Y. Oon, S. Ong, L. Ho, Y. Wong, Y. Oon, H.K. Lehl, Chem. Eng. J. 344, 236 (2018)

[7] F. Scaglione, L. Battezzati, J. Mater. Sci. 50, 5238 (2015)

[8] X. Zhang, T. Peng, S. Song, J. Mater. Chem. A 4, 2242 (2016)

[9] M. AboliGhasemabadi, W.B. Mbarek, O. Casabella, H. RocaBisbe, E. Pineda, L. Escoda, J. Alloys Compd. 741, 240 (2018)

[10] C. Umamaheswari, A. Lakshmanan, N.S. Nagarajan, J. Photochem. Photobiol. B 178, 33 (2018) 
[11] S.I.R. Castillo, C.E. Pompe, J. van Mourik, D.M.A. Verbart, D.M.E. Thies-Weesie, P.E. de Jongh, J. Mater. Chem. A 2, 10193 (2014)

[12] Y. Su, Z. Wu, Y. Wu, J. Yu, L. Sun, C. Lin, J. Mater. Chem. A 3, $8537(2015)$

[13] H. Dong, Z. Jiang, C. Zhang, J. Deng, K. Hou, Y. Cheng, J. Colloid Interface Sci. 513, 117 (2018)

[14] Y. Tang, J. Tian, T. Malkoske, W. Le, B. Chen, J. Mater. Sci. 52, $1581(2017)$

[15] A. Sahoo, S.K. Tripathy, N. Dehury, S. Patra, J. Mater. Chem. A 3, 19376 (2015)

[16] P. Wang, J. Wang, H. Li, H. Yang, J. Huo, J. Wang, J. Alloys Compd. 701, 759 (2017)

[17] S. Schlichter, K. Sapag, M. Dennehy, M. Alvarez, J. Environ. Chem. Eng. 5, 5207 (2017)

[18] C. Zhang, Z. Zhu, H. Zhang, Results Phys. 7, 2054 (2017)

[19] N. Zhou, S. Jiang, T. Huang, Sci. Bull. 64, 856 (2019)

[20] S. Wu, Y. Pan, J. Lu, N. Wang, W. Dai, T. Lu, J. Mater. Sci. Technol. 35, 1629 (2019)

[21] S. Wu, Y. Pan, N. Wang, W. Dai, J. Lu, T. Lu, RSC Adv. 8, 41347 (2018)

[22] J. Wang, Y. Liu, M. Chen, D.V. Louzguine-Luzgin, A. Inoue, J.H. Perepezko, Sci. Rep. 2, 418 (2012)
[23] S. Wu, Y. Pan, N. Wang, T. Lu, W. Dai, Int. J. Miner. Metall. Mater. 26, 124 (2019)

[24] C. Xiang, Z.M. Zhang, H.M. Fu, E.H. Han, J.Q. Wang, H.F. Zhang, G.D. Hu, Acta Metall. Sin. (Engl. Lett.) 32, 1053 (2019)

[25] S.H. Xie, G.Q. Peng, X.M. Tu, H.X. Qian, X.R. Zeng, Acta Metall. Sin. (Engl. Lett.) 31, 1207 (2018)

[26] X. Weng, M. Guo, F. Luo, Z. Chen, Chem. Eng. J. 308, 904 (2017)

[27] Y.T. Wang, J.B. Li, Y.C. Xin, X.H. Chen, M. Rashad, B. Liu, Y. Liu, Acta Metall. Sin. (Engl. Lett.) 32, 932 (2019)

[28] W.M. Haynes, D.R. Lide, T.J. Bruno, CRC Handbook of Chemistry and Physics (2014)

[29] Z.Y. Lv, X.J. Liu, B. Jia, H. Wang, Y. Wu, Z.P. Lu, Sci. Rep. 6, 34213 (2016)

[30] X. Liu, L. Wu, Y. Zhao, Y. Chen, Colloids Surf. A 533, 87 (2017)

[31] L. Wu, X. Liu, Y. Zhao, Y. Chen, Chem. Eng. Sci. 163, 56 (2017)

[32] H. Kim, H. Hong, J. Jung, S. Kim, J. Yang, J. Hazard. Mater. 176, $1038(2010)$

[33] A.N. Bezbaruah, S. Krajangpan, B.J. Chisholm, E. Khan, J.J. Elorza Bermudez, J. Hazard. Mater. 166, 1339 (2009)

[34] W. Gao, M. Liu, S. Chen, C. Zhang, Y. Zhao, Chem. Eng. J. 362, 169 (2019)

[35] Y. Cheng, C. Zhu, Z. Xie, H. Gu, T. Tian, Y. Zhao, J. Colloid Interface Sci. 421, 64 (2014) 